\title{
Confronting Complacency in the Face of Calamity: Mobilizing for the Home Front War against Diabetes
}

\author{
Dean Schillinger* \\ University of California, San Francisco, Center for Vulnerable Populations, Zuckerberg San Francisco General Hospital.
}

Received: November 05, 2016; Accepted: November 24, 2016; Published: December 08, 2016

*Corresponding author: Dean Schillinger, MD, University of California, UCSF Box 1364, San Francisco CA 94143,Fax: 415-206-5586;Tel: 415-206-8940;

E-Mail: dean.schillinger@ucsf.edu

\begin{abstract}
Despite the damage Type 2 Diabetes (DM2) is wreaking on vulnerable families and communities, the US clinical, public health and scientific communities have not yet mobilized for a public health war against DM2. This war requires us to confront our "diabetogenic" society - characterized by sedentary lifestyles, marketing that push diets engorged with processed sugars, and neighborhoods where it is easier and safer to drive than walk. I describe 6 causes for this complacency, and highlight solutions from other recent sociomedical epidemics in which we overcame complacency to generate lifesaving policies. It is time for those fighting DM2 one small clinical battle at a time to become more active in shaping DM2 policy and enlist en masse in the larger policy war against DM2.
\end{abstract}

\section{Introduction}

During the decade-long Iraq and Afghanistan wars, 1,500 US soldiers lost a limb in combat.[1] In that same period, over 730,000 million US residents lost limbs to amputations resulting from Type 2 diabetes (DM2).[2] While the number of home front DM2 amputations exceeds that of the overseas front by a factor of about 500 , and despite abundant evidence that clinicians, patients, and families fight thousands of life- and limb-threatening battles daily, the US clinical and scientific communities have barely begun to mobilize for a public health war against DM2. This war would require us to confront and alter our "diabetogenic" economy and society - characterized by more sedentary work and lifestyles, food and beverage marketing and pricing that push diets engorged with processed sugars, and neighborhoods in which it is far easier and safer to drive than to walk or bike.

As a general internist in a safety-net hospital, approximately half of my patients suffer from DM2. My clinical research focuses on improving the effectiveness of health care for people with DM2, and I have recently completed a term as Chief of the Diabetes Prevention and Control Program for the state of California Department of Public Health. In June of 2014, the global diabetes scientific and clinical communities convened in
San Francisco for the $74^{\text {th }}$ annual American Diabetes Association (ADA) Meeting. Attended by nearly 18,000 individuals from 110 nations, featuring over a thousand presentations, and partially underwritten by 331 vendors and exhibitors, this meeting has grown exponentially in parallel with the DM2 epidemic.

A Special Symposium, entitled Public Initiatives to Improve Health, captured my attention. This session was the only one to address the larger social, structural, and environmental forces that are the engine of this global epidemic. Anticipating its popularity, ADA organizers reserved 2 conjoined ballrooms, with giant screens to amplify the images of Symposium speakers. Stanton Glantz, PhD, a cardiovascular disease epidemiologist widely acknowledged to be a major force behind the war against tobacco, opened the session with "Lessons Learned from the Tobacco World." However, only 18 people, or 1 of every 1000 ADA conference-goers, attended the only symposium to discuss policy and public health approaches to confronting DM2. Dr. Glantz and colleagues, in essence, spoke truth to no one.

In the US, $14.3 \%$ of the adult population have DM2, and $38 \%$ have pre-diabetes, with one half of these projected to progress to DM2 within 10 years.[3] In 2011, 23\% of US teenagers had DM2 or pre-diabetes.[4] DM2 disproportionately affects youth of color: among new DM cases among teens, the proportions that had DM2 were: Native Americans, 85\%; Asian/Pacific Islanders, 72\%; African Americans, 54\%; Latinos, 46\%; and Whites, $15 \%$. [5]Projections suggest that nearly 50\% of African American and Hispanic children born in 2000 will develop DM2 in their lifetime. [6]

The dispiriting showing at the ADA's public policy symposium suggests a dangerous complacency. I propose 6 causes for this complacency, and highlight solutions from recent socio-medical epidemics in which scientific, clinical, public health and lay communities overcame complacency to generate policy actions that saved lives.

Belief in the individual behavioral or genetic paradigms of DM2 causation

Research suggests that health professionals often identify 
genetics, individual behaviors, and personal responsibility as the starting points for discourse about DM2. In a study of 698 print news articles about DM2 causation in 19 US newspapers, only $12 \%$ mentioned socioeconomic or neighborhood factors.[7]Responses to news media narratives describing social causation for DM2 are highly variable, and are strongly associated with political affiliation.[7]The lack of clarity regarding the contributions that social factors play in driving the DM2 epidemic has hampered our willingness to serve as advocates. Additionally, our understanding of how processed food fosters addictive-like behavior is in its infancy, and the food industry employs any army of food and health scientists to generate "evidence" that consumer behavior, not their products, causes illness. This industry-fomented misperception regarding the causes of the public health DM2 crisis mirrors the tactics of the tobacco industry in obfuscating scientific evidence regarding the addictive nature of its product and its health consequences. Scientific evidence ultimately overwhelmed the tobacco industry's mendacious campaigns. We must engage in rigorous research to explicate how the marketing of unhealthy foods and beverages in our environment influence our choices, and how these choices influence both physiology and associated disease burdens.

\section{Cynicism and antipathy regarding the efficacy of public policy solutions}

Unlike curbing tobacco use, regulating the food and beverage industry is viewed by many of us as either unreasonable (fostering a "nanny-state"), or infeasible, since "everyone must eat." As most unhealthy foods are cheap, and since many of our patients cannot afford healthier alternatives, we simply throw up our hands. Former New York City Mayor Bloomberg's 2012 proposal to "downsize" soft drink portions triggered nation-wide public and media outcry, demonstrating Americans' discomfort when a population-level policy attempts to trump individual choice. While international studies have shown the deleterious effects of "Westernization" on DM2 prevalence, [8] the US is so saturated with diabetogenic environments that policy-level, natural experiments are extremely challenging to identify. Nonetheless, we must advocate for well-designed research to test the effects of policy-level or structural interventions. One such study, the Moving to Opportunity Study, demonstrated that changing environmental conditions of a low-income cohort reduced DM2 incidence. [9]Similarly, a large, population-based trial in Spain demonstrated dramatic reductions in incident diabetes among high-risk adults randomized to the Mediterranean diet. [10]

\section{Belief that the causes of diabetes reflect the price of economic well-being}

Our nation's economic infrastructure relies heavily on industries that contribute to a diabetogenic environment --the auto industry, the computer industry, and the fast food industry. In the global context, DM2 is often seen as the "price" of development in emerging economies and a positive reflection of the creation of a middle class.[11]Even in emerging economies, however, DM2 is concentrated in lower socioeconomic groups; sugar exposure, rather than the size of food market economies, explains why urbanization and income have correlated with DM2 rates.[12] We must vehemently counter the argument that unhealthy environments are a necessary byproduct of short term economic vitality, especially because such environments drain the economic vitality of the American workforce due to DM2related disability.

\section{Cogs in the Wheels of the Diabetes-Industrial Complex}

In 1980, former editor of the New England Journal of Medicine, Dr. Arnold Relman, cautioned against a medical-industrial complex that would increasingly influence health policy and clinical care, and contribute to health inequities. DM2 is a significant driver of medical expenditures in the US healthcare system, enriching nearly every sector of the US healthcare economy (clinical visits and procedures, pharmaceutical profits, durable medical equipment, insulin delivery and devices, prosthetics, laboratory and diagnostic services, and basic and clinic research). At the 2014 ADA meeting, there was a paying industry sponsor for every 54 clinician attendees. It is time for us to recognize that, as cogs in the wheel of the diabetes-industrial complex, clinicians benefit from the epidemic. This ethical bind should bolster our resolve to combat DM2 using public health tactics.

Our institutions have an important role to play in this regard. Institutions must break their fiscal dependence on industries that promote DM2, such as the nefarious relationship between the American Academy of Family Physicians and the Cola-Cola company. Exemplary institutional support was provided by the University of California to Dr. Glantz's efforts to publicize the tobacco industry's tactics. This ethos had a ripple effect, enabling a wave of research that accelerated policy advances.

\section{Lack of a powerful and politically active advocacy com- munity}

When I trained at San Francisco General Hospital in the early 1990s, nearly half of my admissions were to the infamous Ward 5A: young gay men with frank AIDS. Over the next 20 years, I participated in an unprecedented degree of productive engagement between public health, clinical, scientific and lay community sectors, collaborating to defeat a common enemy. Most notable was the AIDS Coalition to Unleash Power (ACT UP). ACT UP was an organization --- an army really --- devoted to political action, populated by highly educated and wellconnected people who reflected those affected by the disease. In less than a generation, Ward 5A is devoid of AIDS patients; in their place are young and old patients bearing the ravages of DM2: end-stage kidney disease, amputations, heart disease and stroke. We have replaced one epidemic with another. But because DM2 disproportionately affects low-income populations and ethnic minorities, there is no well-connected, direct action advocacy group for DM2 reflecting the incident demographic. However, a novel and powerful DM2 prevention campaign, The Bigger Picture ( www.thebiggerpicture.org), recently highlighted by the National Academy of Medicine, offers... a promising model for promoting "public health literacy" in DM2. Featuring the authentic voices of youth of color, the campaign decries the 
social and environmental forces that shape the DM2 epidemic in an attempt to ignite social change. [13]

\section{Absence of a "second-hand smoking gun" equivalent}

The discovery that second-hand smoke caused illness in nonsmokers was a pivotal moment in the war on tobacco, reshaping policy and social norms away from individual smokers' rights and their health, to the public's health. Because there is no second-hand smoke equivalent in DM2, the discourse about DM2 remains mired in individual blame and stigma, with accusations of fostering a "nanny state". While DM2 presents no clear avenue to make the argument that it adversely affects the health of others, two facts offer a second-hand smoking gun counterpart. First, DM2 is rapidly engulfing US healthcare expenditures. The annual cost of diabetes in the US has been estimated at $\$ 245$ million. ${ }^{3}$ More than $\$ 700$ of the average American taxpayer's annual income tax levy, regardless of their DM2 status, supports the treatment of DM2.[14]Second, children with DM2, and particularly children of color and low-income children, are innocent victims of our diabetogenic environment. These warwounded provide the most impactful faces, stories, and voices to amplify our advocacy efforts.

\section{Conclusion}

Let us return to the 730,000 who lost their limbs to DM2 over the last decade, and what must be done to honor their loss. That the ADA created a DM2 policy forum with its Public Initiatives to Improve health symposium suggests that DM2 stakeholder institutions recognize that this war needs to be fought on a different level, using different strategies. The fact that the eminent presenters at this symposium faced an army of empty chairs, however, suggests that battle-weary scientists and clinicians have not yet stepped forward to volunteer for a new and prolonged war against the root causes of DM2, and that those directly affected by DM2 have not yet organized to demand change. Much progress in public health over the last century resulted from committed and courageous physicians, nurses and scientists who leveraged their scientific expertise, their credibility, and their daily connection to patients to advance policy agendas to create safer environments where people live, work and play.

Together we must overcome the numerous internal and external obstacles that clinicians face in making a public policy commitment to promote health. The anti-tobacco movement evolved over 40 years, and involved several generations of clinician- and scientist-advocates. Far from futile, our colleaguesin-arms engaged against one of the most powerful and entrenched political lobbies in the US, and continue to win iterative battles. Reframing the DM2 war as a long-term, step-wise effort will be critical for engagement. We can and should develop new alliances across scientific, clinical, public health, business and lay communities, and create effective strategies that squarely confront the unhealthy social, economic, and environmental conditions that are the primary drivers of the DM2 epidemic. The first tangible success in this new war was the 2014 ballot measure to levy an excise tax on Sugar Sweetened Beverages (ssbs) - known contributors to DM2---that passed in the City of Berkeley. Philadelphia passed a similar measure in 2015, and in 2016 these measures won in San Francisco, Albany and Oakland CA, as well as in Boulder CO. Of note, Mexico has witnessed a 12\% reduction in the consumption of ssbs since its measure went into effect, and projections in California suggest that such reductions could yield significant reductions in incident DM2, especially among youth.[15] Because the beverage industry logarithmically outspent the advocates for the tax, future municipal or state measures must receive significant and vocal endorsement by the health profession communities; the consistency of this support will be critical to success at the ballot.

This example suggests that together we can give voice to the silent outrage we witness as DM2 takes its intergenerational toll on our society's vitality, and particularly, on its youngest demographic. Concerned scientists, public health practitioners and clinicians must become more active in affecting policy in their communities, their municipalities, their states and our nation. In addition to the ADA and its Stop Diabetes campaign, a number of professional organizations have activated against DM2, such as the Center for Science in the Public Interest; Union of Concerned Scientists; Physicians for Social Responsibility; and the California Public Health Advocates. It is time for dedicated public health practitioners, scientists and clinicians fighting the DM2 epidemic one small clinical battle at a time to enlist en masse in the larger and longer community and national policy war against DM2.

\section{Acknowledgement}

Dr. Schillinger was supported, in part, by NIH grant P30DK092924

\section{References}

1. Wood D, The World Post. U.S. Wounded In Iraq, Afghanistan Includes More Than 1,500 Amputees. 2012.

2. Coalition A. Fact Sheet: Diabetes and Lower Extremity Amputations. 2008;

3. CDC. National Diabetes Statistics Report. 2014;

4. May AL, Kuklina EV, Yoon PW. Prevalence of cardiovascular disease risk factors among US adolescents, 1999-2008. Pediatrics. 2012;129(6):1035-1041.

5. Bell RA, Mayer-Davis EJ, Beyer JW, D’Agostino RB Jr, Lawrence JM, Linder B, et al. Diabetes in non-Hispanic white youth: prevalence, incidence, and clinical characteristics: the SEARCH for Diabetes in Youth Study. Diabetes care. 2009;32 Suppl 2:S102-s111.

6. Narayan KM, Boyle JP, Thompson TJ, Sorensen SW, Williamson DF. Lifetime risk for diabetes mellitus in the United States. JAMA : the journal of the American Medical Association. 2003;290(14):18841890.

7. Gollust SE, Lantz PM. Communicating population health: print news media coverage of type 2 diabetes. Social science \& medicine. 2009;69(7):1091-1098.

8. Stoddard P, Handley MA, Vargas Bustamante A, Schillinger D. The influence of indigenous status and community indigenous composition on obesity and diabetes among Mexican adults. Social science \& medicine. 2011;73(11):1635-1643. doi: 10.1016/j. socscimed.2011.09.006. 
9. Ludwig J, Sanbonmatsu L, Gennetian L, et al. Neighborhoods, obesity, and diabetes--a randomized social experiment. The New England journal of medicine. 2011;365(16):1509-1519. DOI: 10.1056/ NEJMsa1103216.

10. Salas-Salvado J, Bullo M, Estruch R, Ros E, Covas MI, Ibarrola-Jurado $\mathrm{N}$, et al. Prevention of diabetes with Mediterranean diets: a subgroup analysis of a randomized trial. Annals of internal medicine. Jan 7 2014;160(1):1-10. doi: 10.7326/M13-1725.

11. Narayan KV, Zhang $P$, Kanaya AM, Williams DE, Engelgau $\mathrm{MM}$, Imperatore $\mathrm{G}$ et al. Diabetes: the pandemic and potential solutions. 2006.

12. Basu S, Yoffe P, Hills N, Lustig RH. The relationship of sugar to population-level diabetes prevalence: an econometric analysis of repeated cross-sectional data. PloS one. 2013;8(2):e57873. doi: 10.1371/journal.pone.0057873.

13. Schillinger D. Implications of Health Literacy for Public Health: A Workshop. 2013.

14. Dall TM, Zhang Y, Chen YJ, Quick WW, Yang WG, Fogli J. The economic burden of diabetes. Health affairs (Project Hope). 2010;29(2):297303. doi:10.1377/hlthaff.2009.0155.

15. Mekonnen TA, Odden MC, Coxson PG, Guzman D, Lightwood J, Wang YC, et al. Health benefits of reducing sugar-sweetened beverage intake in high risk populations of California: results from the cardiovascular disease (CVD) policy model. PLoS One. 2013 Dec 11;8(12):e81723. doi: 10.1371/journal.pone.0081723. 